\title{
Instar-specific defensive secretions of stink bugs (Heteroptera: Pentatomidae)
}

\author{
M. Borges ${ }^{\mathrm{a}}$ and J. R. Aldrich ${ }^{\mathrm{b}}$ \\ ${ }^{a}$ EMBRAPA/CENARGEN, Centro Nacional de Pesquisa de Recursos Geneticos e Biotecnologia, CEP 70770, Brasilia \\ (DF, Brazil) and ${ }^{b}$ USDA-ARS, Insect Chemical Ecology Laboratory, Agricultural Research Center-East, B-467, \\ Beltsville (Maryland 20705, USA)
}

Received 23 January 1992; accepted 14 May 1992

Abstract. Defensive secretions (allomones) from first-instar nymphs of stink bugs in the subfamily Pentatominae contain $(E)$-4-oxo-2-decenal as a major constituent, whereas this compound is absent from later instars. In contrast, first instars of Edessa meditabunda (Edessinae) produce allomones like those of later instars. The $\mathrm{C}_{6}$ and $\mathrm{C}_{8}$ (E)-4-oxo-2-alkenals are common, characteristic exocrine compounds of nymphal and adult Heteroptera, but $(E)-4-$ oxo-2-decenal is previously unknown as a major natural product for which a biological role has yet to be established. Key words. Allomone; semiochemical; aggregation; Nezara; Euschistus; Acrosternum; Thyanta; Edessa; Hemiptera.

When molested, immature heteropterans usually retaliate by discharging defensive secretions from dorsal abdominal glands (DAGs) ${ }^{1}$. One of us (M. B.) noticed that the defensive secretion from first-instar nymphs of the southern green stink bug, Nezara viridula, possesses a different odor than do the secretions from second- to fifth-instar nymphs ('instar' sensu Jones ${ }^{2}$; apolysis to apolysis). The large DAGs of nymphs are not retained in the adult stage as active glands; instead, the allomones of heteropteran adults are produced in metathoracic glands. Although metathoracic gland secretions usually differ from the nymphal defensive secretions within a species ${ }^{3}$, qualitative chemical differences between instars of heteropteran nymphs have not, to our knowledge, been previously reported. Therefore, we undertook the present study to compare the allomones of first- and second-instars for several pentatomid species.

\section{Materials and methods}

Bugs. Acrosternum aseadum, Thyanta perditor, Euschistus heros, and Edessa meditabunda were collected near Brasilia and reared continuously in Brazil on green beans (Phaseolus vulgaris), raw shelled peanuts (Arachis hypogaea), and soybean seeds (Glycine max) at $26 \pm 2^{\circ} \mathrm{C}$, $70 \%$ relative humidity, and a $14: 10 \mathrm{~h}$ light-dark cycle. Nezara viridula (originating from Mississippi) was reared in the USA similarly to the phytophagous Brazilian species $^{4}$, and nymphs of Euschistus tristigmus were the offspring of wild adults captured in pheromone-baited traps near Beltsville, MD, USA, in $1990^{5}$.

Extraction. Extracts of first- and second-instar nymphs were prepared by immersing nymphs $(100-1000$ nymphs/sample) in a minimal amount of $\mathrm{CH}_{2} \mathrm{Cl}_{2}$ $(\leq 1000 \mu \mathrm{l})$ for $5 \mathrm{~min}$ and then transferring the extract to a clean cone-bottom vial. The contents of the defensive glands are shed with the exuviae and, for other heteropterans ${ }^{6}$, the DAG secretion from fresh exuviae has been shown to match the composition of secretion obtained from live nymphs. Therefore, for $E$. meditabunda and $N$. viridula, extracts of fifth-instar (last-instar) DAG secretions were also prepared by extracting the exuviae $\leq 24 \mathrm{~h}$ after the ecdysis to the adult stage. One sample of DAG secretion from an irritated fourth-instar $E$. tristigmus nymph was prepared by collecting the secretion in a micropipette under a dissecting microscope.

Chemical analyses. Samples were analyzed by gas chromatography (GC) on a bonded methyl silicone column $\left(0.25 \mu \mathrm{l}\right.$ film, $15 \mathrm{~m} \times 0.25 \mathrm{~mm}$ ID; DB-1 or DB-5 ${ }^{\mathrm{TM}}$, $\mathrm{J} \&$ W Scientific, Folsom, CA) using a Varian $3700 \mathrm{GC}$ with helium as carrier $(40 \mathrm{~cm} / \mathrm{s})$, and a temperature program from $45^{\circ} \mathrm{C}$ for $2 \mathrm{~min}$ to $230^{\circ} \mathrm{C}$ at $15^{\circ} \mathrm{C} / \mathrm{min}$. Reported compound percentages are based on $\mathrm{mV}$ output from the flame ionization detector using a Shimadzu C-R3A recorder. Electron impact mass spectra (MS) were obtained at $70 \mathrm{eV}$ using a Finnigan $4510 \mathrm{GC}-\mathrm{MS}$, equipped with a $30 \mathrm{~m}$ DB-1 column.

The following standards were obtained commercially; $n$-tridecane and tetradecanal (Aldrich Chemical Co., Milwaukee, WI); (E)-2-hexenal, (E)-2-octenal, and (E)-2-decenal (Bedoukian Research Inc., Danbury, CN). (E)-4-Oxo-2-hexenal was synthesized according to Ward and VanDorp ${ }^{7}$, and $(E)$-4-oxo-2-decenal was synthesized after the method of Morizawa et al. ${ }^{8}$. (E)-4-Oxo-2-octenal was identified based on the published MS, and on the retention time of this compound in a DAG extract of late-instar nymphs of the large milkweed bug, Oncopeltus fasciatus (Lygaeidae) ${ }^{9}$.

\section{Results}

All the nymphs examined produce blends of alkanes with alk-2-enals and 4-oxo-alk-2-enals (fig. 1). The DAG secretions of first-instar nymphs were qualitatively different from the secretions of conspecific second instars for Nezara, Acrosternum, Euschistus, and Thyanta spp., but for E. meditabunda the secretions of first- and second-instar nymphs exhibited only slight quantitative variation (figs 2-4). DAG extracts of late-instar nymphs were analyzed by GC for $N$. viridula, E. tristigmus, and E. meditabunda (not shown); the secretions from these fourthor fifth-instar nymphs did not differ significantly from those of conspecific second-instar nymphs. For species expressing instar-specific DAG secretions, the main 


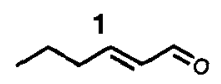

(E)-2-hexenal<smiles>CCC(=O)/C=C/C=O</smiles>

(E)-4-oxo-2-hexenal

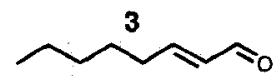

(E)-2-octenal<smiles>CCCCC(=O)/C=C/C=O</smiles>

(E)-4-oxo-2-octenal

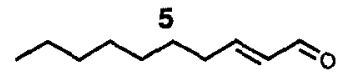

(E)-2-decenal

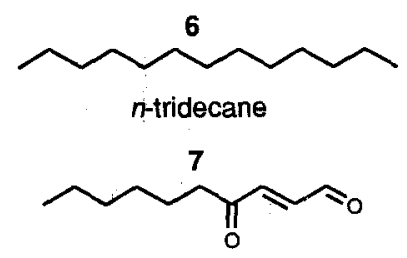

(E)-4-oxo-2-decenal

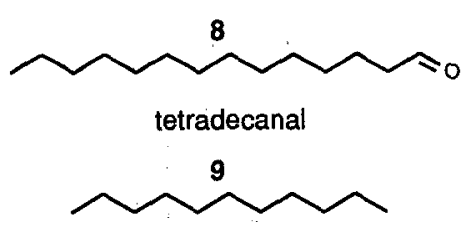

n-undecane
Figure 1. Compounds identified in the dorsal abdominal gland secretions of pentatomid nymphs.

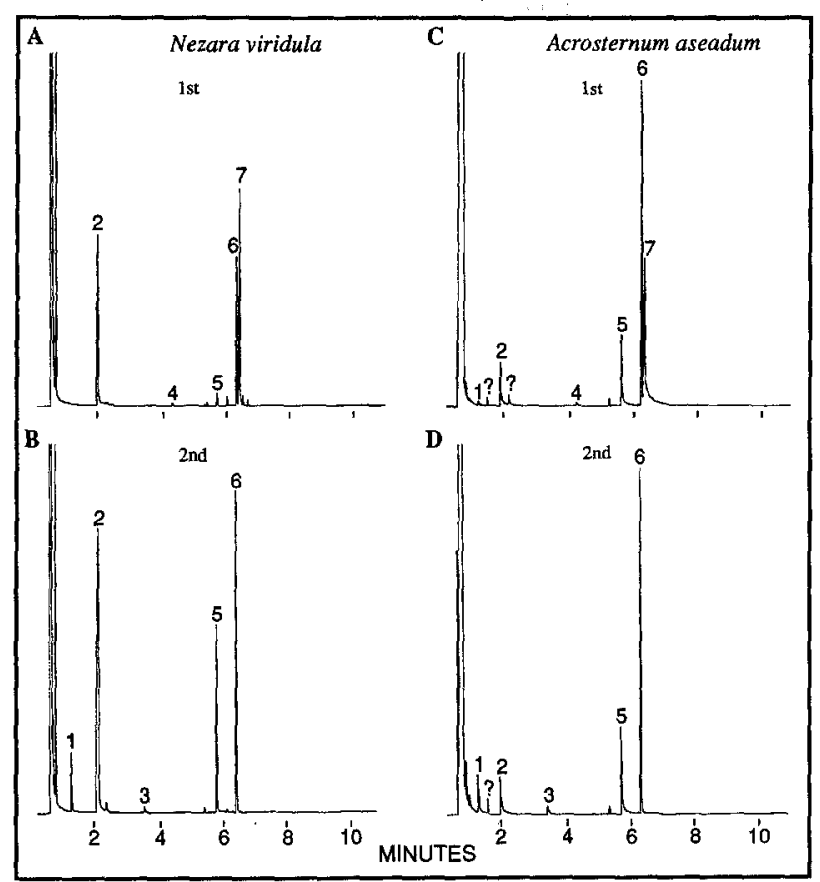

Figure 2. Gas chromatograms of whole-body extracts of $A$ ca 1000 Nezara viridula first instars, $B$ ca $300 N$. viridula second instars, $C$ ca 60 Acrosternum aseadum first instars, and $D$ ca $50 \mathrm{~A}$. aseadum second instars.

For figures 2-4, samples analyzed on a 15-m DB-1 capillary column with attenuation adjusted to bring all exocrine component peaks on-scale (other conditions in text); compound names and structures for numbered peaks as indicated in figure 1.

chemical difference is the inclusion of a component (7) in the exocrine blend from first-instar nymphs that is totally absent from later instars. Of the species examined, this instar-specific chemical difference is most pronounced for $N$. viridula (fig. $2 \mathrm{~A}$ ), with component 7 accounting for over $35 \%$ of the total secretion. Components 1-6 (all previously found in Heteroptera) were identified by MS

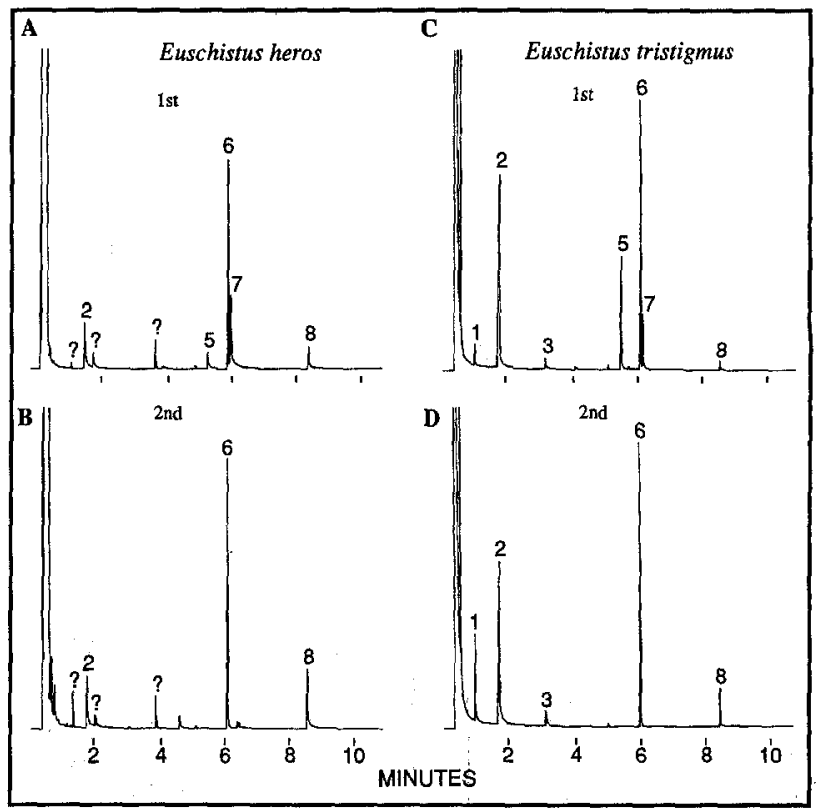

Figure 3. Gas chromatograms of whole-body extracts of $A$ ca $200 E u$ schistus heros first instars, $B$ ca $100 E$. heros second instars, $C$ ca $300 E$. tristigmus first instars, and $D$ ca 300 E. tristigmus second instars.

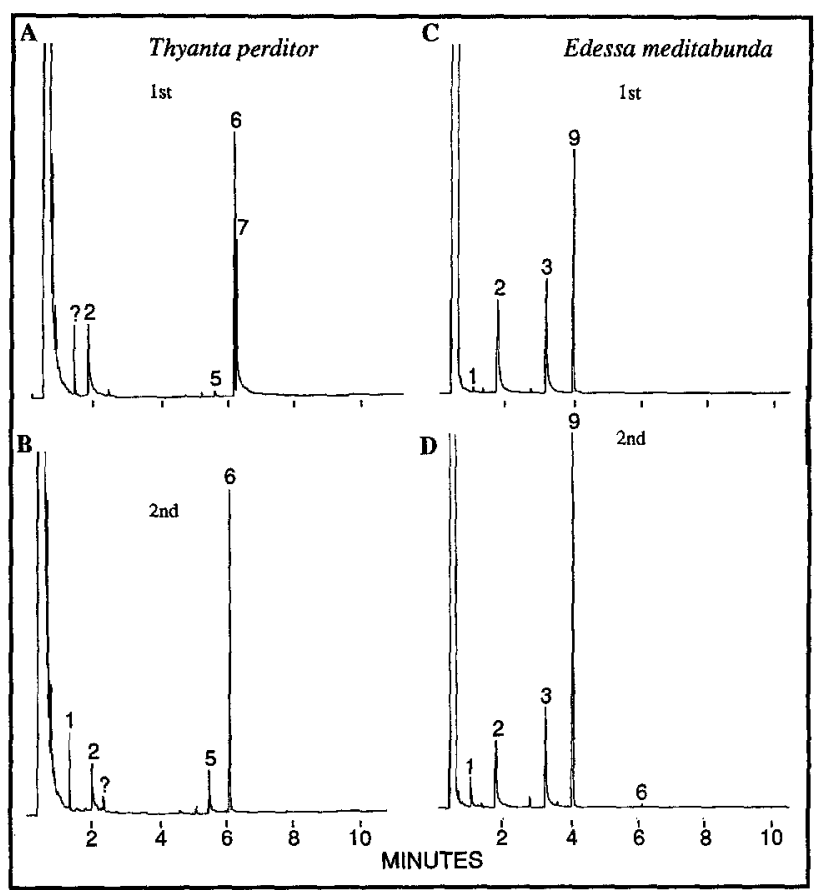

Figure 4. Gas chromatograms of whole-body extracts of $A 25$ Thyanta perditor first instars, $B 11 T$. perditor second instars, $C 20$ Edessa meditabunda first instars, and $D 25 \mathrm{E}$. meditabunda second instars.

comparisons to and GC-coinjection with standards as follows: (E)-2-hexenal (1), (E)-4-oxo-2-hexenal (2), (E)-2-octenal (3), (E)-4-oxo-2-octenal (4), (E)-2-decenal (5), and $n$-tridecane (6).

The species whose first-instars produce $(E)$-4-oxo-2-decenal also appear to contain relatively more of the $C_{6}$ or $C_{8}$ 4-oxo-2-alkenals in their DAG secretions than do secre- 
tions from later conspecific instars. $(E)$-4-Oxo-2-octenal (4), for example, is detectable in DAG secretion from first instars of $N$. viridula and $A$. aseadum, whereas secretions from second instars of these species contain $(E)$-2-octenal (3) with little, if any, 4 (fig. 2). Similarly, (E)-2-hexenal (1) is at most a trace component of the DAG secretions of first instar $N$. viridula, but is a significant component of the secretion from second instars (fig. 2, A and B). Euschistus tristigmus nymphs also conform to this pattern (fig. 3, C and D) in that first instar nymphs produce relatively more of oxo-alkenal 2 than alkenal 1 compared to second-instar nymphs.

A match for the MS of compound 7 was not found on our computerized mass spectral data base. Since the alk2-enals are relatively more abundant in secretion from second-instar southern green stink bug nymphs, particularly $(E)$-2-decenal $(14 \%$ in first instars versus $2 \%$ in second instars) (fig. 2, A and B), we suspected that unknown component 7 could be $(E)$-4-oxo-2-decenal. The MS of 7 is consistent with MS data for the $\mathrm{C}_{6}$ and $\mathrm{C}_{8}$ (E)-4-oxo-2-alkenals ${ }^{7,9}$ : MS $m / z(\%) 168\left(\mathrm{M}^{+}, 4\right)$, 139(78), 125(20), $111(10), 98(67), 83(65), 70(57)$, and $55(100)$. A search of the literature revealed that $(E)$-4oxo-2-decenal had been synthesized as an intermediate for juvenile hormone-II ${ }^{8}$. Synthetic $(E)$-4-oxo-2-decenal gave an MS identical to that for 7 and the natural product coeluted with synthetic $(E)$-4-oxo-2-decenal on DB-1 and DB-5 capillary GC-columns (resolution of tridecane and $(E)$-4-oxo-2-decenal is significantly better on the DB-5 column).

GC comparison of an extract of ca. 50 newly hatched ( $<30$-min-old) first-instar $N$. viridula nymphs to a similar extract of 3-day-old nymphs showed a) that old first instars produce nearly 50 times more DAG secretion per insect than newly hatched nymphs and, b) the ratio of $(E)$-4-oxo-2-decenal/(E)-2-decenal is much greater for old first instars (ca 50:1) than for young nymphs (ca 2.5:1).

DAG extracts of first-instar nymphs of $A$. aseadum, $E$ schistus spp., and T. perditor (figs 2-4) all contain 7 as a major constituent, and the ratio of 4-oxo-2-alkenal/ 2 -alkenal is greater for first instars than for the secretion of second instars. $n$-Tridecane (6) is the major alkane in the DAG secretions of these species, as in the Nezara DAG secretions, but the secretions from Euschistus spp. are unusual in two respects. First, tetradecanal (8) is a significant secretory component of first- and second-instar Euschistus nymphs. Second, although $(E)$-2-decenal (5) is an abundant component in the DAG secretion from first instars, this compound is totally lacking in the secretion of second instars (fig. 3), nor was 5 detected in the DAG secretion from the E. tristigmus fourth-instar nymph (not shown). On the contrary, nymphs of $E$. meditabunda produce DAG secretions that are chemically alike, without $(E)$-2-decenal or $(E)$ 4-oxo-2-decenal (first and second instars: fig. 4,C and $\mathrm{D}$; fifth instars not shown). In addition, secretions from these nymphs contain $n$-undecane (9) instead of $n$-tridecane.

\section{Discussion}

(E)-4-Oxo-2-decenal has previously only been reported as a trace component of the defensive secretion of fifthinstar nymphs of a cotton stainer bug (Pyrrhocoridae) ${ }^{10}$. We have found that $(E)$-4-oxo-2-decenal is a major constituent of the exocrine secretions of first instars in four of the five pentatomid species examined. The stink bugs having unique first-instar DAG secretions are members of the subfamily Pentatominae, while the lone exceptional species (E. meditabunda) belongs to the Edessinae. A more complete appreciation of the distribution of instarspecific DAG secretions, and the validity of this phenomenon as a chemotaxonomic character, awaits a broader sampling of the group.

Comparison of the composition of DAG secretions from newly hatched $N$. viridula nymphs to those from 3-dayold first instars reveals that young nymphs contain much less secretion in the DAGs than do older nymphs, and the proportion of $(E)$-2-decenal is greater for young nymphs than for old first-instar nymphs. Therefore, it appears reasonable that $(E)$-4-oxo-2-decenal is biosynthesized via oxidation of $(E)$-2-decenal, perhaps by enzymes secreted into the reservoirs of these glands as occurs in the metathoracic gland of adult heteropterans ${ }^{11}$. The total absence of $(E)$-2-decenal from the DAG secretions of second-instar Euschistus nymphs is perplexing.

The aggregation and dispersal behaviors of first-stage nymphs of $N$. viridula have been thoroughly investigated $^{12-14}$, but the presence of $(E)$-4-oxo-2-decenal as a major DAG exocrine component of first instars was overlooked ${ }^{15}$ apparently because this oxo-alkenal coeluted with tridecane under the GC conditions employed $^{12}$. After hatching, nymphs of $N$. viridula ${ }^{12}$ and other pentatomines ${ }^{14,16}$ aggregate on top of the egg shells. Two to three days after emergence the first instars wander from their empty egg mass and reaggregate, often forming clumps of bugs piled on top of each other thereby resisting desiccation ${ }^{12,17}$. In $N$. viridula, the initial egg-shell aggregation is maintained by tactile stimulation ${ }^{14}$ and separated emerging nymphs do not reaggregate $^{12}$, whereas the secondary aggregation is primarily chemically mediated for $N$. viridula ${ }^{12}$ and for Eurydema spp. (Pentatominae) ${ }^{16}$. In addition, first-instar aggregations of $N$. viridula away from their egg shells were dispersed by high concentrations of DAG secretions from conspecific first instars ${ }^{12}$, and first-instar Eurydema spp. dispersed when exposed to concentrated extracts of conspecific second and third instars ${ }^{18}$. For $N$. viridula nymphs, $n$-tridecane reportedly serves as a bifunctional pheromone promoting aggregation at low concentration and dispersal at high concentration ${ }^{12}$. A similar conclusion was reached for Eurydema spp. nymphs (even though the extract tested against first instars was prepared from second and third instars) except that 
(E)-2-hexenal was implicated as the bifunctional pheromone ${ }^{16,18}$. On the other hand, Edessa meditabun$d a$ is an unusual stem-feeding stink bug ${ }^{19}$ whose first instars stand side-by-side around the egg shells after hatching, appear to be about twice the size of pentatomine first instars, and do not subsequently form multilayered reaggregations ${ }^{17}$.

In view of the exaggerated tendency for first-instar pentatomines to congregate, we initially suspected that (E)-4-oxo-2-decenal functions as an aggregation pheromone. However, our preliminary attempts to induce the formation of first-instar aggregations in $N$. viridula nymphs using whole-body extracts have thus far failed to substantiate this hypothesis. In Eurydema spp., first instars became alarmed when exposed to DAG volatiles from second and third instars of either Euryde$m a$ or Nezara spp. ${ }^{18}$, so it is improbable that $(E)$-4-oxo2 -decenal is an essential alarm pheromone component of first instars. Early instars of $N$. viridula suffer the greatest mortality ${ }^{20}$, but first-instar $N$. viridula nymphs may be relatively less vulnerable to predation than later instars ${ }^{13}$. Previous chemical data for the allomones of adult and immature heteropterans indicate that nymphal defensive secretions are enriched in high-molecular weight constituents, presumably because the flightless immatures require longer-lasting protection ${ }^{1}$. Thus, the expression of $(E)$-4-oxo-2-decenal and the concomitant enrichment of $\mathrm{C}_{6}$ and $\mathrm{C}_{8}$ 4-oxo-2-alkenals in the allomones of first-instar pentatomines may be an extension of this evolutionary trend, providing a fortified irritant for the most vulnerable stage of these insects.
Acknowledgments. We thank Drs J. E. Oliver and J. P. Kochansky, USDA-ARS, Beltsville, for synthesis of $(E)$-4-oxo-2-decenal and $(E)$-4-oxo2-hexenal, respectively. Vanice Lopes dos Santos, Debora Siqueira Moll, Regina Maria Alves, Vinicius Ferreira Carvalho, and Helio Moreira dos Santos helped with field collecting and laboratory rearing of the bugs, for which we are grateful. Dr T. J. Henry (USDA Systematic Entomology Laboratory) identified Acrosternum aseadum. Discussions with Drs Walker Jones and D. B. Thomas, USDA-ARS, Weslaco, Texas, were very helpful. We also thank EMBRAPA and CNPq for financial support.

1 Aldrich, J. R., A. Rev. Ent. 33 (1988) 211

2 Jones, J. C., Ann. ent. Soc. Am. 71 (1978) 491.

3 Aldrich, J. R., and Yonke, T. R., Ann. ent. Soc. Am. 68 (1975) 955.

4 Aldrich, J. R., Oliver, J. E., Lusby, W. R., Kochansky, J. P., and Lockwood, J. A., J. exp. Zool. 244 (1987) 171.

5 Aldrich, J. R., Hoffmann, M. P., Kochansky, J. P., Lusby, W. R., Eger, J. E., and Payne, J. A., Envir. Ent. 20 (1991) 478.

6 Aldrich, J. R., Neal, J. W. Jr, Oliver, J. E., and Lusby, W. R., J. chem. Ecol. 17 (1991) 2307.

7 Ward, J. P., and VanDorp, D. A., Recueil 88 (1969) 989.

8 Morizawa, Y., Kanakura, A., Yamamoto, H., Hiyama, T., and Hitosi, N., Bull. chem. Soc. Jap. 57 (1984) 1935.

9 Games, D. E., Jackson, A. H., Millington, D. S., and Staddon, B. W., Adv. Mass Spectrom. 6 (1974) 207

10 Farine, J. P., Bonnard, O., Brossut, R., and Le Quere, J. L., J. chem. Ecol. 18 (1992) 65.

11 Aldrich, J. R., Blum, M. S., Hefetz, A., Fales, H. M., Lloyd, H. A., and Roller, P., Science 201 (1978) 452.

12 Lockwood, J. A., and Story, R. N., Ann. ent. Soc. Am. 78 (1985) 474. 13 Lockwood, J. A., and Story, R. N., Envir. Ent. 15 (1986) 739.

14 Lockwood, J. A., and Story, R. N., Ann. ent. Soc. Am. 79 (1986) 963.

15 Lockwood, J. A., and Story, R. N., Ann. ent. Soc. Am. 80 (1987) 686.

16 Ishiwatari, T., Appl. Ent. Zool. 11 (1976) 38

17 Borges, M., and Aldrich, J. R., unpublished data.

18 Ishiwatari, T., Appl. Ent. Zool. 9 (1974) 153.

19 Panizzi, A. R., and Machado-Neto, E., Ann. ent. Soc. Am., submitted (1991).

20 Kiritani, K., and Hokyo, N., Jap. J. appl. Ent. Zool. 6 (1962) 124.

$0014-4754 / 92 / 090893-04 \$ 1.50+0.20 / 0$

(C) Birkhäuser Verlag Basel, 1992 